\title{
First Hour Initiation of Breast Feeding \& Associated Factors, among Mothers at Post Natal Ward in Fort Portal Referral Hospital, Uganda
}

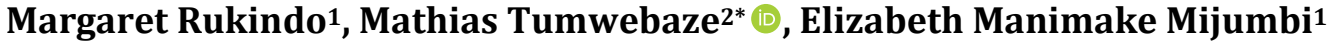 \\ ${ }^{1}$ Kabarole Local Government, Fort Portal, Uganda \\ ${ }^{2}$ Department of Public Health, Bishop Stuart University, Mbarara, Uganda \\ Email: rukindomargret@gmail.com, *mathiastumwebaze@gmail.com, bethmake@yahoo.com
}

How to cite this paper: Rukindo, M., Tumwebaze, M. and Mijumbi, E.M. (2021) First Hour Initiation of Breast Feeding \& Associated Factors, among Mothers at Post Natal Ward in Fort Portal Referral Hospital, Uganda. Open Journal of Epidemiology, 11, 1-15.

https://doi.org/10.4236/ojepi.2021.111001

Received: October 2, 2020

Accepted: December 12, 2020

Published: December 15, 2020

Copyright $\odot 2021$ by author(s) and Scientific Research Publishing Inc. This work is licensed under the Creative Commons Attribution International License (CC BY 4.0).

http://creativecommons.org/licenses/by/4.0/

(c) (i) Open Access

\begin{abstract}
Background: Breast milk is recommended as the best feeding option to neonates and infants for it confers immunological benefits that help to reduce neonatal and infant morbidities and mortalities. WHO recommends that all infants should start breast feeding within one hour of birth i.e. early initiation of breast feeding (EIBF). Unfortunately, studies show that less than $40 \%$ of infants in resource limited settings Uganda inclusive are initiated on breast feeding practice, with no documented study done in Kabarole district to assess the problem. This study therefore, set out to establish the prevalence and associated factors with the practice of first hour initiation of breast feeding at Fort Portal Regional Hospital, Kabarole district, Uganda. Methods: With a cross-sectional design, we collected data from 330 post natal mothers and their live-born infants at Fort Portal Regional Referral hospital from $5^{\text {th }}-20^{\text {th }}$ August 2019. With a standard interviewer administered tool, mothers who initiated breast feeding within the first hour after delivery of their newly born babies responded with yes and those that did not with a no. Prevalence of one hour initiation was got considering infants that were initiated on breast within one hour over the total live birth times 100 to get the percent prevalence. With Stata version 13 software, statistically significant relationships of the predisposing factors were determined at a $p$-value $(p \leq 0.05)$ at bivariate and at multivariate regression coefficient. Results: A total of 330 postnatal mothers targeted for this study, $100 \%$ response rate was covered. Mothers' age ranged from 18 - 45 years with mean age $31 \mathrm{SD} \pm 6$. The prevalence of initiation of breast feeding in the first hour of birth was $68 \%$, a third of $(32 \%)$ mothers had not initiated breast feeding in the first hour. A half (50\%) of the direct predisposing factors for non-initiation of timely breastfeeding were due
\end{abstract}


to birth asphyxia, almost a quarter $23 \%$ due to mother's ill health and $7 \%$ due mother not being guided by the health worker on what to do. In this study mothers' knowledge and awareness of the practice were very low at $20 \%$ while that of health workers was fair at 53\%. Social demographic factors that influence $1^{\text {st }}$ hour breast feeding practice were; young maternal age being less than 34 years, mothers occupation being self-employed $(83 \%)$ or unemployed (73\%) with 3 times higher odds of initiating breastfeeding within $1^{\text {st }}(\mathrm{OR}=3$, $p=0.003$ ) than working class mothers (civil servants). Marital status of mothers being married (73\%) significantly influenced early breastfeeding practice $(p=0.001)$. Health workers' knowledge of the practice was significantly associated (OR $\left.=2.7, X^{2}=11.32,{ }^{\star} p=0.00078\right)$ with enforcement of mother initiation of breast feeding in first hour compared to the less knowledgeable ones. Conclusion: The practice of timely initiation of breastfeeding at Fort Portal Regional Referral hospital at 68.2\% was sub-optimal against WHO universal practice recommendations. Mothers' low knowledge on timely initiation of breast feeding practice was the most deterrent factor for first hour initiation of breastfeeding practice. Providing breastfeeding counselling to all mothers during ANC and training on best breastfeeding practices and counselling skills for health staff at Fort Portal Referral hospital are urgent recommendation in this study to improve the practice.

\section{Keywords}

Practice of First Hour Initiation of Breast Feeding, Postnatal Mothers, Fort Portal Regional Referral Hospital

\section{Introduction}

World Health Organization and UNICEF recommend initiation of breastfeeding within the first hour after birth [1]. This is because colostrum is a known perfect first food for newborns, which is considered as an infant's first immunization [2], however, there are limited studies showing the proportion of mothers practicing this and factors influencing the practice.

Recent, WHO 2017 guidelines [3] emphasize that all newborn babies should be placed on skin-to-skin contact with their mothers' immediately after birth and initiate breastfeeding within one hour of birth. Early initiation of breast feeding together with Kangaroo mother care [4] improves neonatal survival and reduces the child morbidity.

Breastfeeding remains the cornerstone of infant and young child survival nutrition and development even in the face and scare of highly infectious and emerging diseases like COVID-19 [5]. WHO recommends that mothers with suspected or confirmed COVID-19 should be encouraged to initiate or continue to breastfeed [5]. Mothers should be cancelled that the benefits of breastfeeding substantially outweigh the potential risks for corona virus transmission, this is because, through breast milk a baby acquires passive immunity IgA antibodies 
from the mother that can help the child fight most childhood infections [6]. More studies have continued to demonstrate safety of breastfeeding practice that contains antibodies that help protect infants from primary causes of child morbidity and mortality worldwide [7]. In 2015, neonatal mortality represented approximately $45 \%$ of under-5 deaths [8]

In Sub Saharan Africa, poor breast-feeding practices contribute to neonatal and infant mortality [9]. It was found out that breastfeeding as a determinant of infant health and nutrition, saves up to 1.5 million infant lives annually. Although breastfeeding is nearly universal in sub-Saharan Africa, early initiation of breastfeeding is rarely practiced [9]

First hour initiation of breastfeeding in Uganda remains low at a rate of $36.4 \%$ compared to the national target of $100 \%$ [10]. Findings by Bbale [11], one study in Uganda revealed that on average, $56 \%$ and $46 \%$ initiated breastfeeding in the first hour and practiced exclusive breastfeeding respectively while 50\%, and $75 \%$ terminated breastfeeding at 18 , and 26 months respectively.

In Kabarole region, study area, there are limited documented studies on the practice of first hour initiation of breast feeding. Fort Portal Regional Referral Hospital in Kabarole district serves seven districts in the region that include: Kabarole, Kyenjojo, Ntoroko, Bundibugyo, Kasese, Kyegegwa, Kamwenge and Bunyangabu; notably the practice of first hour initiation has remained low regardless of location of hospitals. With no documented study on Factors associated with the practice of first hour initiation of breast feeding in Kabarole region. The researcher aimed at establishing the prevalence and associated factors with the practices of first hour initiation of breast feeding in order to provide information and data for improved practice among postnatal mothers.

\section{Methodology}

\section{Study setting}

The study was conducted at Fort Portal Regional Referral Hospital Uganda postnatal ward. This hospital serves seven districts in the region with a current bed capacity of 350 . On average the hospital conducts $10-15$ deliveries daily including caesarean sections. It is also on record that Fort Portal Regional Referral hospital registered high fresh still birth number of 201/1000 deliveries and had the highest number of maternal deaths (53) in FY 2017/18 compared to other regional referral hospitals in Uganda [12].

Study design and sample

An institutional based cross-sectional study design was used. Quantitative and qualitative data collection techniques were applied to collect data from 330 post natal mothers in a hospital. The cross-sectional survey design was adopted for this study because it also provides a systematic description that is factual and accurate [13]. The cross sectional survey data was collected from a sample of 330 respondents at a single point in time from $5^{\text {th }}$ August- $20^{\text {th }}$ August 2019 at Fort Portal Regional referral Hospital that serves a population of over 10,000,000 people [14] and the hospital receives an average of 5600 mothers per year [15]. 


\section{Study population}

The study population comprised of mothers attending and those admitted on postnatal ward at Fort portal regional referral hospital. The hospital delivers an average of 12 mothers a day, 360 a month and approximately 43,200 mothers a year. Doctors, midwives and nurse who attend to deliveries and to postnatal mothers were purposively selected and 30 of them included in the study.

\section{Sample size estimation}

Leslie Kish, 1965 [16] statistical sampling formula for single population cross sectional studies was used. The level of confidence of the study 95\%, margin of error $5 \%$, the proportion ( $\mathrm{p}$ ) was 0.33 which estimated the proportion of post natal mothers (33\%) according to Ministry of Health Uganda 2014 post natal study reports. Taking into consideration a non-response rate of $10 \% 330$ post natal mothers with an infant less than 6 months of age were selected.

\section{Sampling procedure}

Fort Portal Regional Referral hospital was selected purposively based on the high numbers of mothers delivering from the hospital and the wider area of service coverage (7) districts in the region. The wards with eligible respondents were also purposively identified for serving postnatal mothers. Mothers were selected systematically, sampled and picked as every second mother arriving at the ward as per the daily registration. Those in prenatal care were all included as long as a live birth was got. This was maintained until the required sample was obtained within the study period.

\section{Inclusion criteria}

Mother's eligibility for inclusion in the study was based on verbal consent to participate in the study. Only postnatal mothers at postnatal ward and those in prenatal care who resided within the 7 districts of the Ruwenzori region were included in the study.

Exclusion criteria: Mothers who resided outside the 7 districts of the Rwenzori region were excluded in the study. Mothers who did not consent to be interviewed and Mothers who had a caesarian section delivery under general anesthesia were also excluded from the study.

Study variables

\begin{tabular}{cc}
\hline Independent variables & Dependent variable. \\
\hline Mothers knowledge of the practice & \\
Mothers age & Mother practice of initiation of \\
Mothers religion & Breastfeeding within $1^{\text {st }}$ hour of \\
New born Baby health status (healthy or unhealthy & Birth or \\
Intervening variables & \\
Health workers knowledge on early initiation of \\
breast feeding in the first hour of birth and \\
enforcement of the practice among mothers
\end{tabular}




\section{Data Collection Instruments}

A structured interviewer administered questionnaire was used to get information from the post natal mother and a semi structured questionnaire used to get data from health workers.

\section{Validity}

An interviewer administered tool used to collect data in this study was given to ten (10) senior researchers to evaluate the relevance of each item in the instrument to the objectives of the study. Each item was rated on the inter rater scale according to Waltz as very relevant (4), quite relevant (3), somewhat relevant (2) and relevant (1). Validity was determined using the content validity index (CVI). Content Validity index equals item rated 4 or 3 by the experts divided by total number of items in the questionnaire 14/20. In this particular study the CVI was 0.7 and this was considered valid

\section{Reliability}

The questionnaire was pre-administered to 10 post natal mothers at Bukuku Health Centre level IV before actual data collection at the Regional Referral Hospital. The results got were run through stata and reliability coefficient of the tool determined using Cronbach's Alpha Coefficient. The value was 0.731, thus the instrument was considered reliable.

\section{Computation of prevalence of first hour initiation of breast feeding}

Using a standard structured questionnaire mothers who initiated breast feeding within the first hour after delivery of their newly born babies responded with yes and those that never initiated breast feeding in first hour responded with a no. The total number of respondents (yes) was used as numerator while the total number of live births (sample size) in the study period was used as denominator. Prevalence was finally arrived at as follows

$$
P=\frac{\text { numberofchildren initiated in first hour breast feeding in the sample }}{\text { total number of live births in the sample }} * 100
$$

\section{Ethical consideration:}

The study protocol was reviewed and approved by the Institutional Review Board (IRB) at Faculty of Health Sciences of Uganda Christian University. An introductory letter was issued permitting the researchers to conduct the study at Fort Portal Regional Referral Hospital. With the subsequent approval of the Hospital administration. Informed Verbal consent was then sought and obtained from each post-natal mother before participating in the study.

\section{Data analysis:}

Quantitative data analysis was done for descriptive and inferential statistics at three levels:- univariate, bivariate and multivariate using STATA version 13, Descriptive statistics were entailed in determination of measures of central tendency, the mean, measure of dispersion range and standard deviation but also for frequency distributions and percentages. For Inferential statistics, the statistical significance of the relationship was determined at a p-value $(p \leq 0.05)$. For Significant relationships at Bivariate level, correlation analysis at multivariate by 
correlation coefficient analysis was performed on the outcome variable i.e. Initiated breastfeeding in the first hour or not with various independent variables such as maternal age, occupation, marital status and knowledge levels.

\section{Results}

Table 1, presents the Social demographic factors influencing mother's preparedness on initiation of first hour breast feeding. The study targeted 330 post-natal mothers for the assessment. Researchers collected data from all the 330 targeted number with response rate of $100 \%$ as showed in Table 1 . The demographic features of the unit of inquiry focused parameters with responses on age, level of education, religion, marital status and occupation. Slightly more than a half $170(51.5 \%)$ were aged between 25 - 34, followed by $99(30 \%)$ in age bracket $35-44$ years, in general mothers age ranged from 18 - 46 years with mean age $31 \mathrm{SD} \pm 6$.

Almost a half of the respondents $158(47.9 \%)$ were married, a third 112 (33.9\%) were protestants, for occupation 100 (30.3\%) were self-employed while 98 (29.7\%) were public servants.

Table 2 presents mothers demographic variables and status of breast feeding within $1^{\text {st }}$ hour of delivery. Breastfeeding in the $1^{\text {st }}$ hour of birth was more prevalent $72 \%$ among mothers aged 35 to 40 years, followed by $67 \%$ of those aged 25 34 years. Married mothers $73 \%$ tended to breastfeed more comparatively to singles $65 \%$. As regards occupation, early initiation of breast feeding was frequently reported among the self-employed $83 \%$. From religious perspective, the practice was frequently reported among Protestants 77\% Catholics, 73\% and lowest in Muslims 49\%

Table 1. Social demographic factors influencing mothers' preparedness on initiation of first hour breast feeding $(\mathrm{n}=330)$.

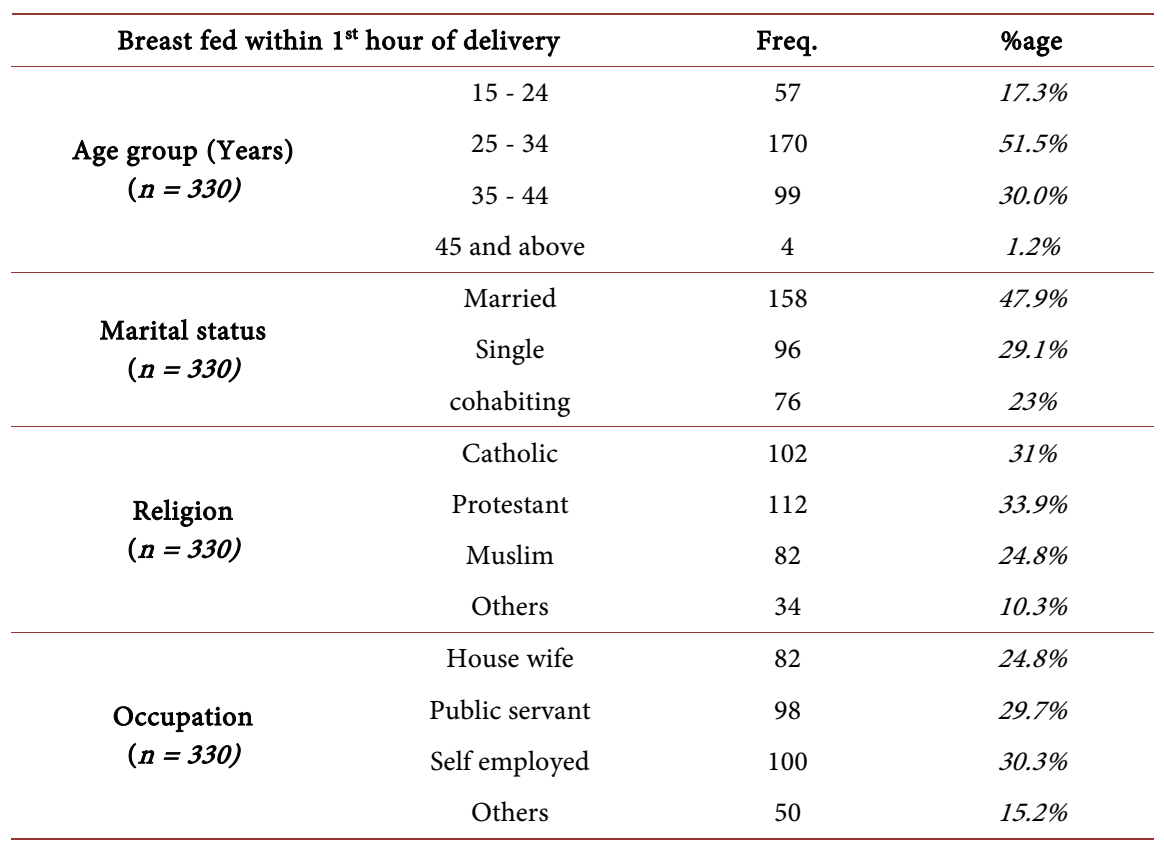


Table 2. Respondents by category against the practice of first hour initiation of breast feeding. $(n=330)$.

\begin{tabular}{|c|c|c|c|c|c|c|c|}
\hline \multirow{2}{*}{\multicolumn{2}{|c|}{$\begin{array}{l}\text { Breast fed within } 1^{\text {st }} \\
\text { hour of delivery }\end{array}$}} & \multicolumn{2}{|c|}{ Yes } & \multicolumn{2}{|c|}{ No } & \multirow[t]{2}{*}{$X^{2}$} & \multirow[t]{2}{*}{$P$-value } \\
\hline & & Freq. & \%age & Freq. & \%age & & \\
\hline \multirow{5}{*}{$\begin{array}{l}\text { Age group (Yrs) } \\
\quad(n=330)\end{array}$} & $18-24$ & 34 & $65 \%$ & 23 & $35 \%$ & \multirow{5}{*}{0.7} & \multirow{5}{*}{0.001} \\
\hline & $25-34$ & 114 & $67 \%$ & 56 & $33 \%$ & & \\
\hline & $35-40$ & 59 & $72 \%$ & 20 & $28 \%$ & & \\
\hline & $41-44$ & 10 & $33 \%$ & 10 & $67 \%$ & & \\
\hline & 45 and above & 2 & $33 \%$ & 2 & $67 \%$ & & \\
\hline \multirow{3}{*}{$\begin{array}{c}\text { Marital status } \\
\quad(n=330)\end{array}$} & Married & 115 & $73 \%$ & 43 & $27 \%$ & \multirow{3}{*}{12} & \multirow{3}{*}{0.001} \\
\hline & Single & 62 & $65 \%$ & 34 & $35 \%$ & & \\
\hline & cohabiting & 46 & $61 \%$ & 30 & $39 \%$ & & \\
\hline \multirow{4}{*}{$\begin{array}{l}\text { Religion } \\
(n=330)\end{array}$} & Catholic & 74 & $73 \%$ & 28 & $27 \%$ & \multirow{4}{*}{2} & \multirow{4}{*}{0.0001} \\
\hline & Protestant & 86 & $77 \%$ & 26 & $23 \%$ & & \\
\hline & Muslim & 40 & $49 \%$ & 42 & $51 \%$ & & \\
\hline & Others & 24 & $71 \%$ & 10 & $29 \%$ & & \\
\hline \multirow{4}{*}{$\begin{array}{l}\text { Occupation } \\
(n=330)\end{array}$} & House wife & 56 & $72 \%$ & 26 & $28 \%$ & \multirow{4}{*}{9} & \multirow{4}{*}{0.2} \\
\hline & Public servant & 59 & $55 \%$ & 39 & $45 \%$ & & \\
\hline & Self employed & 85 & $83 \%$ & 15 & $17 \%$ & & \\
\hline & Others & 31 & $64 \%$ & 19 & $36 \%$ & & \\
\hline
\end{tabular}

\section{From Table 3,}

Most mothers who were aware of breast feeding in the first hour after birth were more likely to breast feed in the first hour after birth $70 \%$ compared to the mothers who were not aware $30 \%$.

Prevalence of first hour initiation of breastfeeding among postnatal mothers.

The prevalence of first hour initiation of breast feeding was got using formula below.

$$
\begin{gathered}
P=\frac{\text { numberofchildren initiated on first hour breast feeding in the sample }}{\text { total number of live births in the sample }} * 100 \\
P=\frac{225}{330} \times 100 \quad P=68.2 \%
\end{gathered}
$$

Figure 1, shows that $225(68.2 \%)$ of post natal mothers practiced one hour initiation of breast feeding at Fort Portal Regional Referral hospital while 105 (31.8\%) of the babies born in the hospital were not breast fed within the first hour.

Figure 2 shows that half of the postnatal mothers 24 (50\%) who did not breast feed their babies in the first hour was because the babies were born with birth asphyxia, followed by 11 (23\%) ill \& 7 (15\% did not know and were not told. 
Table 3. Respondents' awareness about first hour initiation of breast feeding vs actual practice of first hour initiation of breast feeding.

\begin{tabular}{ccccccc}
\hline \multicolumn{5}{c}{ First hour breast feeding practice } & Total & Pearson corr. \\
\hline $\begin{array}{c}\text { Ever had about first hour } \\
\text { initiation of breast feeding? }\end{array}$ & Yes & $\%$ & No & $\%$ & Total & 0.3 \\
Yes & 162 & 70 & 69 & 30 & 231 & \\
No & 31 & 30 & 68 & 70 & 99 & \\
Total & 193 & 100 & 137 & 100 & 330 & \\
\hline
\end{tabular}

Time post natal mothers initiated $\mathrm{B} /$ feeding

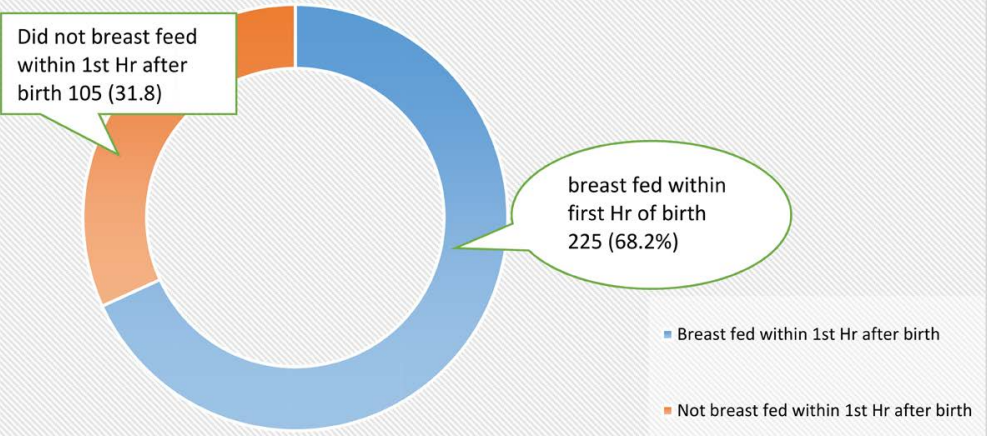

Figure 1. Prevalence of first hour Breast feeding among new born babies in FPRRH.

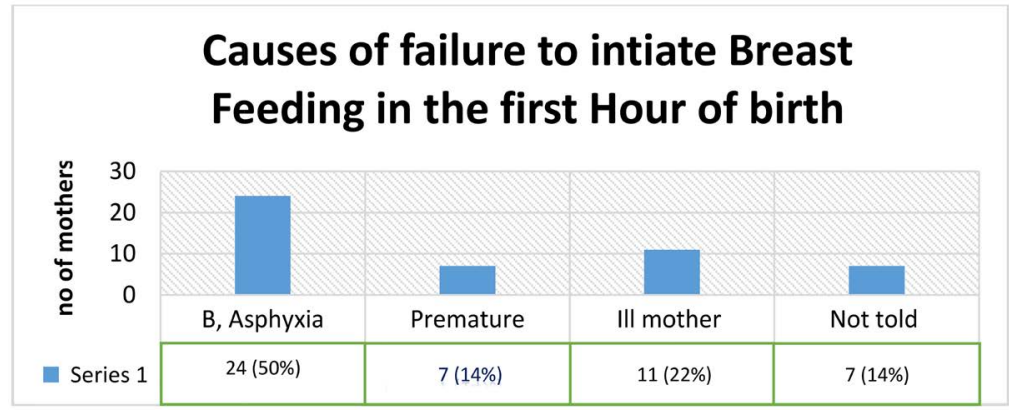

Figure 2. Causes of failure to breast feed in the first hour of Birth $n=49$.

\section{Mothers' knowledge on first hour initiation of breast feeding.}

Mother's knowledge about first hour initiation of Breast feeding was assessed on 10 important attributes of breast feeding as documented in WHO guidelines and recommendations on first hour initiation and exclusive breast feeding. That breast milk is highly nutritious, confers passive immunity to an infant, a baby should be exclusively breast fed for 6 months, clean the breast nipple before Breast feeding, knowing at least one effect of not breast feeding, HIV exposed infants and breast feeding, strengthening baby mother bond, that even the highly educated should breast feed, the rich should also breast feed, frequent breast feeding also is done at night.

On the scale of 1 - 10 number of responses, 1 - 3 (10\% - 30\%) was categorized 
as very low knowledge or no knowledge, $4-6(40 \%-60 \%)$ as some knowledge and $7-10(70 \%-100 \%)$ as good knowledge. Table 4 presents findings on mothers' knowledge on first hour initiation of Breast feeding.

Figure 3 shows that almost half of the respondents 162 (49\%) had very little knowledge considered as no knowledge about the meaning, procedure, and benefits of first hour initiation of breast feeding about a third ( $31 \%$ had some knowledge, only 66 (20\%) post natal mothers were knowledgeable of the practice.

\section{Health workers knowledge on first hour initiation of breast feeding}

Clear understanding of health workers of $\mathrm{WHO}$ and $\mathrm{MOH}$ breast feeding guidelines and policies would directly translate into increased uptake of the practice among the post natal mothers. This would be as a result of health workers enforcing the practice during ANC visits. Health workers knowledge was therefore assessed on the $\mathrm{WHO}$ and $\mathrm{MOH}$ guidelines and polices about first hour initiation of breast feeding practice as well as the health outcomes of the practice.

Table 5 presents the knowledge levels of Medical officers and midwives who work in the post natal care on the $1^{\text {st }}$ hour initiation of breastfeeding

Table 5 shows that medical officers were better off knowledgeable about First hour initiation of breast feeding 6/10 (60\%) compared to midwives where only a half 10/20 (50\%) were knowledgeable. Over all knowledge level of the staff at the Regional Referral Hospital was slightly above average 16/30 (53\%).

Table 6(a) shows that about a half $14(46 \%)$ of the Health workers were not knowledgeable about FHIBF and more than a half 16 (54\%) were knowledgeable. Of those knowledgeable, 15 (94\%) demonstrated a high likely hood of enforcing initiation of breast feeding, compared to 5 (36\%) among the non-knowledgeable

Table 6(b) gives analysis output from the bivariate analysis using Epi-Info StatCalc. Shows a statistically significant association between a health worker being knowledgeable of the benefits of breastfeeding and enforcement of initiation of breastfeeding in the first hour of birth $\mathrm{OR}=27 X^{2}=11.32,2$ tailed ${ }^{\star} \boldsymbol{p}=$ 0.00078 .

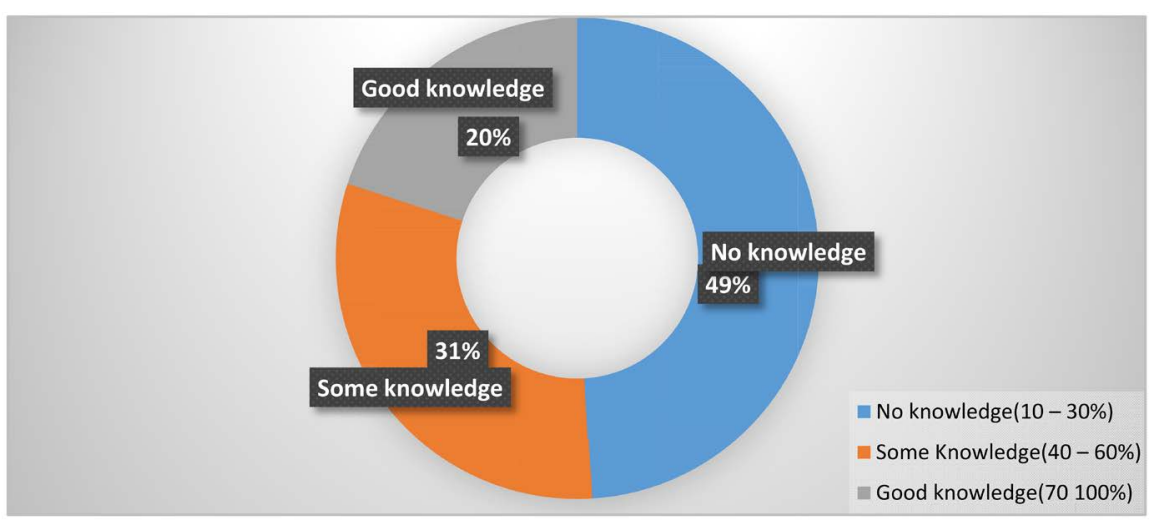

Figure 3. Knowledge of Post-natal mothers on the first hour initiation of breast feeding. 
Table 4. Criteria for Post-natal mothers' knowledge assessment on first hour initiation of $\mathrm{B} /$ feeding.

\begin{tabular}{ccccc}
\hline $\begin{array}{c}\text { Number of questions } \\
\text { answered }\end{array}$ & Knowledge level & $\begin{array}{c}\text { Number of questions } \\
\text { passed (Percentage pass) }\end{array}$ & Frequency & Percentage \\
\hline \multirow{2}{*}{10} & Very low knowledge & $1-3(10 \%-30 \%)$ & 162 & $49 \%$ \\
& Some knowledge & $4-6(40 \%-60 \%)$ & 102 & $31 \%$ \\
& Good knowledge & $7-10(70 \%-100 \%)$ & 66 & $20 \%$ \\
Total & & & 330 & $100 \%$ \\
\hline
\end{tabular}

Table 5. Awareness and Knowledge of health workers on first hour initiation of breast feeding.

\begin{tabular}{cccccc}
\hline \multirow{2}{*}{$\begin{array}{c}\text { Qualification of } \\
\text { health worker }\end{array}$} & Number & \multicolumn{2}{c}{ Knowledgeable } & \multicolumn{2}{c}{ Not knowledgeable } \\
\cline { 3 - 6 } & & Frequency & \%age & Frequency & \%age \\
\hline Midwife/ Nurse & 20 & 10 & $50 \%$ & 10 & $50 \%$ \\
Medical officer & 10 & 6 & $60 \%$ & 4 & $40 \%$ \\
Total & 30 & 16 & $53 \%$ & 14 & $47 \%$ \\
\hline
\end{tabular}

Table 6. (a) Health workers knowledge and likelihood to enforce first hour breast feeding. (b) Epi-Info StatCalc- $2 \times 2$ analysis output.

(a)

\begin{tabular}{ccccccc}
\hline \multicolumn{2}{c}{ Level of knowledge } & \multicolumn{3}{c}{ Enforce First Hour Breast feeding } \\
\hline & Frequency & $\%$ & Yes & \%ge & No & $\% g e$ \\
\hline Knowledgeable & 16 & $54 \%$ & 15 & $94 \%$ & 1 & 6 \\
Not knowledgeable & 14 & $46 \%$ & 5 & $36 \%$ & 9 & $64 \%$ \\
\hline
\end{tabular}

(b)

\begin{tabular}{cccc}
\hline Variables & Enforced IFHBF & Not Enforced 1FHBF & Totals \\
\hline Knowledgeable & $15(94 \%)$ & $1(6 \%)$ & $16(100 \%)$ \\
Not Knowledgeable & $5(36 \%)$ & $9(64 \%)$ & $14(100 \%)$ \\
Total & $20(100 \%)$ & $10(100 \%)$ & $30(100 \%)$ \\
\hline
\end{tabular}

$\mathrm{OR}=2.7 X^{2}=11.322$ tailed $^{*} \boldsymbol{p}=\mathbf{0 . 0 0 0 7 8}$.

\section{Discussion}

The study aimed; at identifying factors associated with mothers' practice of breast feeding initiation in the first hour of birth, the prevalence of first hour initiation of breastfeeding and health workers' knowledge so as to enforce first hour breast feeding initiation among mothers.

In this study $68 \%$ mothers had initiated breast feeding in the first hour of birth while $32 \%$ had not, demographic factors associated with this good practice included, mothers' occupation, maternal age, marital status as being married, religion as being a Christian and Health workers knowledge of the practice

Table 1 demographically, shows that slightly more than half (51.5\%) of those who initiated Breast feeding in the first hour were aged between 25 - 34 years. 
Detailed analysis revealed a mother being young below 34 years was strongly associated with initiation of breast feeding in the first hour of birth. $\mathrm{OR}=2, \mathrm{p}=$ 0.001 . In contrast however, studied done elsewhere in Nepal [17] and in Tanzania [18] the risk of delayed breast feeding was reportedly higher among young women. Delayed breastfeeding among young aged women [18] was attributed to inexperience and feeling of insecurity among young mothers. The finding of young age being associated with early initiation of Breastfeeding is a unique finding, probably the level of education exposure in young people compared to old women in Ugandan setting could explain that.

In this study about three quarters (73\%) of respondents who breast fed in the first hour after giving birth were married compared to the cohabiting and single mothers. Further analysis showed a statistical correlation between marriage and first hour breast feeding (Pearson $x^{2} .0 .18, P=0.001$, $\mathrm{OR}=0.6$ ), this agrees with findings of previous researchers [19]. This may be so because the married couples tend to get encouragement from their spouses and families of the husband. This may have a postive effect with an obvious advanctage over cohabiting and single mothers . A significant relationshioship was also established beween mothers occupation and the practice of first hour initiation. self emplyed mothers (83\% unemployed $(72 \%)$ had 3 times higher odds to breastfeed their babies in the first hour after birth compared to civil servants (55\%). ( $0 \mathrm{R}=3, P=0.0003$, $x^{2}=8$ ). this is probably due to the fact that, the self employed mothers have full autonomy to make their own decisions, attend antenatal and get sensitized on the benefits of early initiation of breast feedig. Simirlary, working mothers in Pakistan were more likely to delay initiation of breast feeding compared to non -working group [20].

Suprisingly, our study Figure 1 demonstrated a seemigly higher prevalence $68 \%$ of mothers initiating breastfeeding in the first hour of birth. Recent descriptive analysis in 57 low-and middle-income counties established a 50\% prevalence of early initiation of breastfeeding in sub-Saharan Africa. Furthermore studies one in Adis-Ababa Ethiopia established a prevalence of $58.3 \%$. Much as our finding on prevalence of $68 \%$ is above what has been found in other studies mentioned above, it is still much lower than World Health Organization (WHO) recommends of every mother (100\%) to initiate breastfeeding within one hour of birth [21]. Inquiry in the reasons for low uptake of the service /initiation revealed that a half $(50 \%)$ of those who never initiated breast feeding in first one hour was because babies were born with birth asphyxia while $23 \%$ reported mother being ill and 15\% did not know and were not told. Other studies have demonstrated mother's condition after birth as a direct determinant of whether breast feeding is initiated early or not. Specifically, Caesarean section has been pointed out as a critical barrier to breast feeding initiation before or after the first hour [22], this is as a result of post-operative care that tend to interrupt the contact between the mother and her new born in the post-partum period. In our study however, caesarian section delivered mothers were excluded.

In this study, mother's knowledge on benefits of Breast feeding was low at 
$20 \%$ and $31 \%$ with some knowledge with almost a half $49 \%$ not knowledgeable at all. Low mothers' knowledge was a critical determinant factor for the low practice. Relatedly, health workers knowledge on first hour initiation of breast feeding should be high if they are to enforce the practice among mothers. In this study slightly more than a half (53\%) of health worker were knowledgeable of breastfeeding initiation. Health workers low knowledge was unexpected finding given the key role played in enforcing the Breast feeding practice. Medical officers had a comparatively higher knowledge at $60 \%$ compared to midwives at $50 \%$. The difference in knowledge level could be due to increased exposure of medical officers to $\mathrm{MOH}$ polices guidelines and ability to interpret and internalize such policies. Bivariate analysis of the Health workers knowledge (Table 6(b)) and enforcement of early breastfeeding showed a statistically significant relationship $\left(\mathrm{OR}=27 X^{2}=11.32{ }^{\star} p=0.00078\right)$ of Knowledgeable health workers being more like to enforce initiation of breast feeding compared to less knowledgeable.

\section{Conclusion}

In this study, the practice of timely initiation of breastfeeding at Fort Portal Regional Referral hospital was suboptimal at $68.2 \%$. This is against WHO recommendations of the practice as universal among mothers giving birth to live babies. The main factors for the delay in starting breast feeding in the first hour were social demographic in nature as follows: low mother's knowledge on timely initiation of breast feeding practice, a mother not being married, state of mother after delivery and low health workers knowledge.

\section{Recommendations}

1) Raising awareness and knowledge of mothers by providing breastfeeding counselling to all mothers during ANC by MCH staff in the district.

2) Conduct intensified training and mentorships on best breastfeeding practices and counselling skills for health staff in post-natal clinic at Fort Portal Referral hospital

3) Popularize the good practice of first hour initiation of Brest Feeding among the VHTs in the district who will subsequently reach every corner of the district sensitizing women of child bearing age about the practice.

\section{Ethical approval and consent to participate in the study}

The ethical approval of the study was obtained from the Institutional Review Board (IRB) at Faculty of Health Sciences, Uganda Christian University Mukono accompanied by letter of introduction. The ethical letter was presented to the District Health officer Kabarole and Director of Fort Portal Regional Referral Hospital and a written go-ahead to conduct the study was obtained. In this study only mothers who consented were interviewed and the information provided was kept confidential and not exposed to anyone outside the study. 


\section{Limitations}

Mothers who delivered by caesarean section were discriminated by the study design because of their health status post-operatively. However, being operated upon is not a desired situation to such mothers and their right to initiate early breast feeding is inevitably deprived. It was therefore not possible to establish the knowledge levels and practice of such mothers in this study.

\section{Acknowledgements}

We are highly indebted to the District Health officer Kabarole, and the Director of Fort Portal Regional Referral hospital who permitted the study in the district and Hospital respectively. The research assistants who participated in data collection are not forgotten. We owe this study to the mothers and infants in Kabarole and beyond who participated in this study at the hospital.

\section{Conflicts of Interest}

The authors declare no conflicts of interest regarding the publication of this paper.

\section{References}

[1] World Health Organization (2003) Global Strategy for Infant and Young Child Feeding. World Health Organization, Geneva. http://www.who.int/nutrition/publications/infantfeeding/9241562218/en/

[2] Legesse, M., Demena, M., Mesfin, F. and Haile, D. (2015) Factors Associated with Colostrum Avoidance among Mothers of Children Aged Less than 24 Months in Raya Kobo District, North-Eastern Ethiopia: Community-Based Cross-Sectional Study. International Breastfeeding Journal, 9, Article No. 189. https://doi.org/10.1186/s13006-014-0025-2

[3] World Health Organization (2017) Guideline: Protecting, Promoting and Supporting Breastfeeding in Facilities Providing Maternity and Newborn Services. World Health Organization, Geneva. http://apps.who.int/iris/handle/10665/259386

[4] World Health Organization (2015) WHO Recommendations on Interventions to Improve Preterm Birth Outcomes. World Health Organization, Geneva.

[5] World Health Organization (2020) Breastfeeding and COVID-19. World Health Organization, Geneva.

[6] World Health Organization (2020) Clinical Management of COVID-19: Interim Guidance. World Health Organization, Geneva.

[7] Carvalho, M.L., Boccolini, C.S., Oliveira, M.I.C. and do Carmo Leal, M. (2016) The Baby-Friendly Hospital Initiative and Breastfeeding at Birth in Brazil: A Cross Sectional Study. Reproductive Health, 13, Article No. 119. https://doi.org/10.1186/s12978-016-0234-9

[8] Takahashi, K., Ganchimeg, T., Ota, E., Vogel, J.P., Souza, J.P., Laopaiboon, M., et al. (2017) Prevalence of Early Initiation of Breastfeeding and Determinants of Delayed Initiation of Breastfeeding: Secondary Analysis of the WHO Global Survey. Scientific Reports, 7, Article No. 44868. https://doi.org/10.1038/srep44868

[9] Kalisa, R., Malande, O., Nankunda, J. and Tumwine, J.K. (2015) Magnitude and 
Factors Associated with Delayed Initiation of Breastfeeding among Mothers Who Deliver in Mulago Hospital, Uganda. African Health Sciences, 15, 1130-1135. https://doi.org/10.4314/ahs.v15i4.11

[10] United Nations Children's Fund (2019) Why Family-Friendly Policies Are Critical to Increasing Breastfeeding Rates Worldwide. United Nations Children's Fund, New York City.

[11] Bbale, E. (2014) Determinants of Early Initiation, Exclusiveness and Duration of Breastfeeding in Uganda. Journal of Health, Population and Nutrition, 32, 249-260.

[12] Ministry of Health (2018) Annual Health Sector Performance Report 2017/18. Ministry of Health, Kampala.

[13] Amin, E.M. (2005) Social Science Research, Conception and Analysis. Makerere University Press, Kampala.

[14] Uganda Bureau of Statistics (2019) Statistical Abstract.

[15] Fort Portal Regional Referral Hospital Data Bank (2018/2019)

[16] Leslie, K. (1965) Survey Sampling. John Wiley and Sons, Inc., New York

[17] Patel, A., Badhoniya, N., Khadse, S., Senararatha, U., Agho, K.E., Diblley, M.J., et al. Infant and Young Child Feeding Practices Indicators and Determinants of Poor Feeding Practices in Nepal: Secondary Data Analysis of National Family Health Survey 2005-06. Food and Nutrition Bulletin, 31, 314-333. https://doi.org/10.1177/156482651003100221

[18] Denis, C.-L. (2002) Breastfeeding Initiation and Duration: A 1990-2000 Literature Review. Journal of Obstetric, Gynecologic \& Neonatal Nursing, 31, 12-32. https://doi.org/10.1111/j.1552-6909.2002.tb00019.x

[19] Uganda Bureau of Statistics (200) Uganda Demographic and Health Survey 2006. Uganda Bureau of Statistics, Kampala, 467 p.

[20] Hazir, T., Akram, D.S., Nisar, Y.B., Kazim, N., Agho, K.E., Abbasi, S., et al. (2013) Determinants of Sub Optimal Breastfeeding Practices in Pakistan. Public Health Nutrition, 16, 659-672. https://doi.org/10.1017/S1368980012002935

[21] World Health Organization (2017) Guideline: Protecting, Promoting and Supporting Breastfeeding in Facilities Providing Maternity and Newborn Services. World Health Organization, Geneva.

[22] Rowe-Murray, H.J. and Fisher, J.R. (2002) Baby Friendly Hospital Practices: Caesarean Section Is Persistent Barrier to Early Initiation of Breast Feeding. Birth, 29, 124-131. 


\section{Abbreviations}

$\begin{array}{ll}\text { ANC } & \text { Antenatal Care } \\ \text { EIBF } & \text { Early Infant Breast Feeding } \\ \text { FPRRH } & \text { Fort Portal Regional Referral Hospital } \\ \text { MCH } & \text { Maternal and Child Health } \\ \text { MOH } & \text { Ministry of Health } \\ \text { MOH } & \text { Ministry of Health Uganda } \\ \text { UBOS } & \text { Uganda Bureau of Statistics } \\ \text { VHTs } & \text { Village Health Teams } \\ \text { WHO } & \text { World Health Organisation }\end{array}$

